\title{
FULECO: UM ESTUDO SEMIÓTICO DA MASCOTE DA COPA DO MUNDO DA FIFA BRASIL 2014
}

\author{
Roger Costa Pellizzoni \\ Viviane Pellizzon Agudo Romão \\ Richard Perassi Luiz de Souza, Dr. \\ Francisco Antonio Pereira Fialho, Dr. \\ Marília Matos Gonçalves, Dra. \\ UFSC, PósDesign
}

\begin{abstract}
Resumo
O presente trabalho é resultado de um estudo semiótico da mascote da Copa da Fédération Internationale de Football Association (FIFA) a realizar-se no Brasil em 2014, inspirado no animal Tatubola, visando um entendimento do mesmo em seus aspectos semânticos. A escolha de tal personagem se deve a sua grande evidência atual na mídia, por ter sido escolhido o representante brasileiro na próxima Copa do Mundo e pela polêmica que se criou em torno do fato. A metodologia utilizada compreende as etapas de identificação dos elementos-chave no personagem e a análise dos mesmos de acordo com a bibliografia especializada apresentada no decorrer do artigo. Por fim, objetiva-se um esclarecimento se a imagem da mascote Tatu-bola fornece informações gráfico-visuais e semióticas suficientes para que o público a compreenda como tal.
\end{abstract}

Palavras-chave: Semiótica; Mascote; Design Gráfico

\begin{abstract}
This work is the result of a study of semiotic Cup mascot of Fédération Internationale de Football Association (FIFA) to be held in Brazil in 2014, inspired by the animal Tatu-ball, aiming an understanding of it in their semantic aspects. The choice of such a character is due to its large current evidence in the media, have been chosen by the Brazilian representative at the next World Cup and the controversy that has arisen around the fact. The methodology comprises the steps of identifying key elements in the analysis of the same character according to the relevant literature presented throughout the article. Finally, the objective is a clarification if the picture Mascot Tatu-ball provides information graphic-visual and semiotic enough for the audience to understand as such.
\end{abstract}

Keywords: Semiotics; Mascot; Graphic Design 


\section{INTRODUÇÃO}

O termo mascote vem do occitano 'mascoto' e foi incorporado ao idioma francês pelo poeta Frédéric Mistral, que recebeu o prêmio Nobel de literatura de 1904 justamente por seu trabalho de resgate e promoção da língua provençal.

O responsável pela difusão do vocábulo em âmbito internacional, entretanto, foi o Edmond Audran, que em 1880 compôs uma ópera de grande sucesso chamada 'La Mascotte' - ou 'A Bruxinha', reforçando assim o significado original daquela expressão: sortilégio, adivinhação, feitiçaria.

Contudo, o emprego de imagens de animais e outros, por parte de grupos ou indivíduos, como um 'amuleto de sorte', ou mesmo de exaltação das qualidades que os identificassem, é muito anterior. Já na baixa-idade média o uso de tais representações era comum entre a nobreza feudal, origem da brasonaria.

Antes disso, o peixe, a âncora e a imagem de um pastor de ovelhas já eram utilizados como símbolos da igreja cristã primitiva, ainda durante o império romano. A igreja se utilizou da simbologia animal, também, como ferramenta de catequização em seus 'bestiários', entre os séculos $\mathrm{V}$ e XII.

Os símbolos, como expressão da representação mítica, fazem parte do inconsciente humano e certamente o acompanham desde há milênios. A linguagem humana é repleta de simbolismos e, muitas vezes, o homem se utiliza de sinais ou imagens menos descritivas que "servem, apenas, para indicar os objetos a que estão ligados." (JUNG, 1991)

Com a industrialização, a aplicação de imagens de animais, vegetais, seres mitológicos e até pessoas como representação de empresas e de produtos alçou este simbolismo a um novo estágio. O racionalismo deu nova dimensão ao seu uso e foi preciso conceituar e estruturar este recurso. Procurou-se, então, distinguir o 'símbolo', uma versão única e estática da figura, de um 'personagem', agora já detentor de movimento, personalidade e 'vida' própria (STRUNCK, 2001, v. 1, p.73). Nasceu, então, a mascote, como a conhecemos hoje.

Esta nova condição de 'personalidade' concedida à mascote, fez com que, aos poucos, ela transferisse seu aspecto, geralmente empático e positivo, às marcas e produtos que representava. (TELES; NUNES; GOMES, 2007). A partir daí, e de forma intensificada após a segunda metade do século XX - com a expansão vertiginosa de novas indústrias, marcas e produtos de consumo, à mascote e seu uso foi conferido o objetivo de criar, junto ao 
seu público-alvo, mas não só, uma identificação fundamentada na relação de fidelização à marca e ao consumo de produtos a ela vinculados.

Para isso, os profissionais de marketing, design e comunicação "orbitam no universo idílico do consumidor, procurando por pontos de maior identificação." (COSTA, 2008).

Pacheco (2005) afirma que, dentro da ótica mercadológica de fidelização do consumidor, a mascote, ou personagem, precisa, "transmitir confiabilidade, simpatia, segurança, serenidade, modernidade, entre outros, sem esquecer do traço humano importante para a marca."

O uso da mascote em eventos esportivos uma das primeiras mascotes ligadas ao esporte foi utilizada pelo Chicago Cubs, clube de beisebol norte-americano. Uma fantasia representando um filhote de urso polar foi usada por um homem, chamado de Bearman, pela primeira vez em 1908, como mostra a figura abaixo. Apesar de nunca ter sido oficializada e jamais ter sido popular entre os fãs, a mascote tem sido aplicada em alguns produtos do clube, desde então.

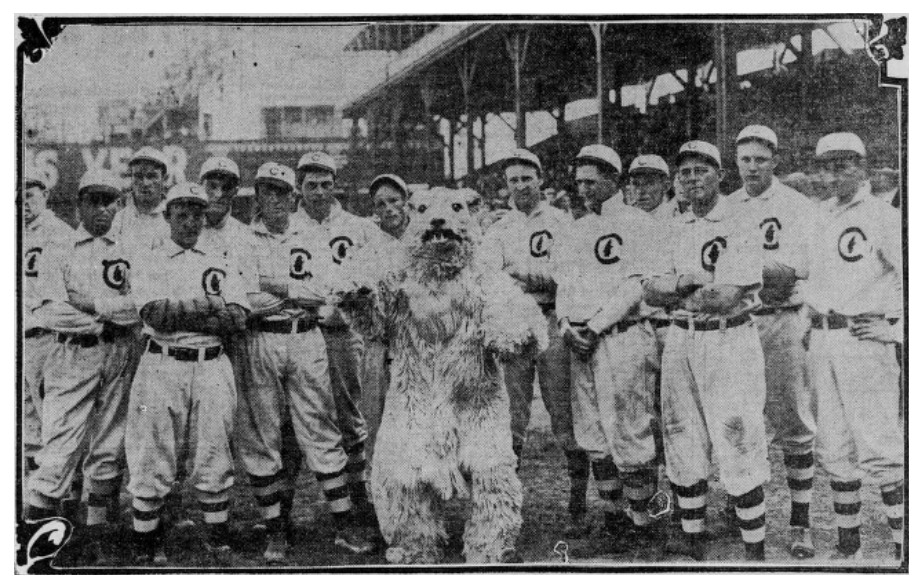

Figura 1: Registro da mascote do Chicago Cubs durante um jogo, em 11 de julho de 1908. Fonte: http://agatetype.typepad.com/agate_type/mascots/

A primeira aparição de uma mascote em um evento esportivo internacional aconteceu nos Jogos da X Olimpíada, em 1932, na cidade Los Angeles, também nos Estados Unidos da América. Contudo, essa não era uma figura representada por um desenho ou fantasia e, sim, um cão sem raça definida, chamado Smoky.

O emprego da figura de uma mascote, com as características concebidas atualmente, associada a um evento esportivo de grande projeção ocorreu apenas em 1966, na VII Copa do Mundo da FIFA, na Inglaterra. A figura de um leão, animal símbolo do país, presente, 
inclusive, no Real Brasão do Reino Unido - juntamente com um unicórnio, foi chamada de World Cup Willie e representada vestindo uma camisa com as cores e listras da bandeira nacional, com a inscrição "WORLD CUP", em alusão à competição esportiva. A partir de então, praticamente todos os eventos esportivos internacionais, ou mesmo regionais e nacionais com alguma estrutura organizativa, especialmente de marketing, vem utilizando o recurso do uso de mascotes.

Ainda que não exista uma determinação pré-estabelecida, ficando a cada comissão organizadora definir os critérios de configuração do personagem, de modo geral esses procuram traduzir alguma característica natural ou cultural do país ou cidade-sede da competição esportiva, como a fauna, a flora ou alguma manifestação do folclore local.

Frequentemente, este personagem, quando uma representação da fauna ou da flora, recebe características antropomórficas, a fim de criar empatia com o público, especialmente o infanto-juvenil, no intuito de despertar o interesse pelo consumo de mercadorias vinculadas ao evento. Neste sentido, uma política bastante severa de licenciamento de uso é empregada pelos responsáveis pela organização do evento, que reserva os direitos de exploração do personagem, por meio de registros de patentes e de marcas em nível internacional.

Para que se possa ter uma noção do grau de importância no faturamento de empresas e instituições organizadoras com a comercialização de produtos licenciados, foram criados mais de 4 mil produtos diferentes durante os Jogos da XXIX Olimpíada, evento multiesportivo realizado em Beijing, capital da República Popular da China, alcançando uma receita de aproximadamente $\mathrm{R} \$ 600$ milhões com a sua comercialização, só naquele país. Os mais vendidos, segundo o comitê organizador, foram os produtos relacionados aos cinco mascotes dos Jogos: Huanhuan, Yingying, Nini, Beibei e Jingjing, que representavam os 5 elementos tradicionais da cultura chinesa (metal, madeira, água, fogo e terra), além das cinco cores dos anéis que fazem parte do símbolo olímpico (amarelo, azul, verde, vermelho e preto).

A concisão de valorização a que as mascotes foram elevadas, passando de um personagem-símbolo a um produto de forte apelo de consumo, exigiu que novas teorias e conceituações no âmbito do marketing, do design e da comunicação fossem criadas.

Gomes (2002) traz uma nova classificação de mascotes, dependendo do grau de vinculação com a empresa, marca ou produto para a qual foi criada: 'produto-personagem', em geral o próprio produto; 'personagem-produto', onde a mascote possui uma relação de exclusividade com um determinado produto, não sendo usado por outros produtos da mesma empresa ou marca; o 'personagem-gama', que pode ser usado em uma série de produtos da 
mesma marca; e o 'personagem-signo', mais próximo do 'símbolo' associado a uma marca, já conceituado anteriormente por Strunck (2001).

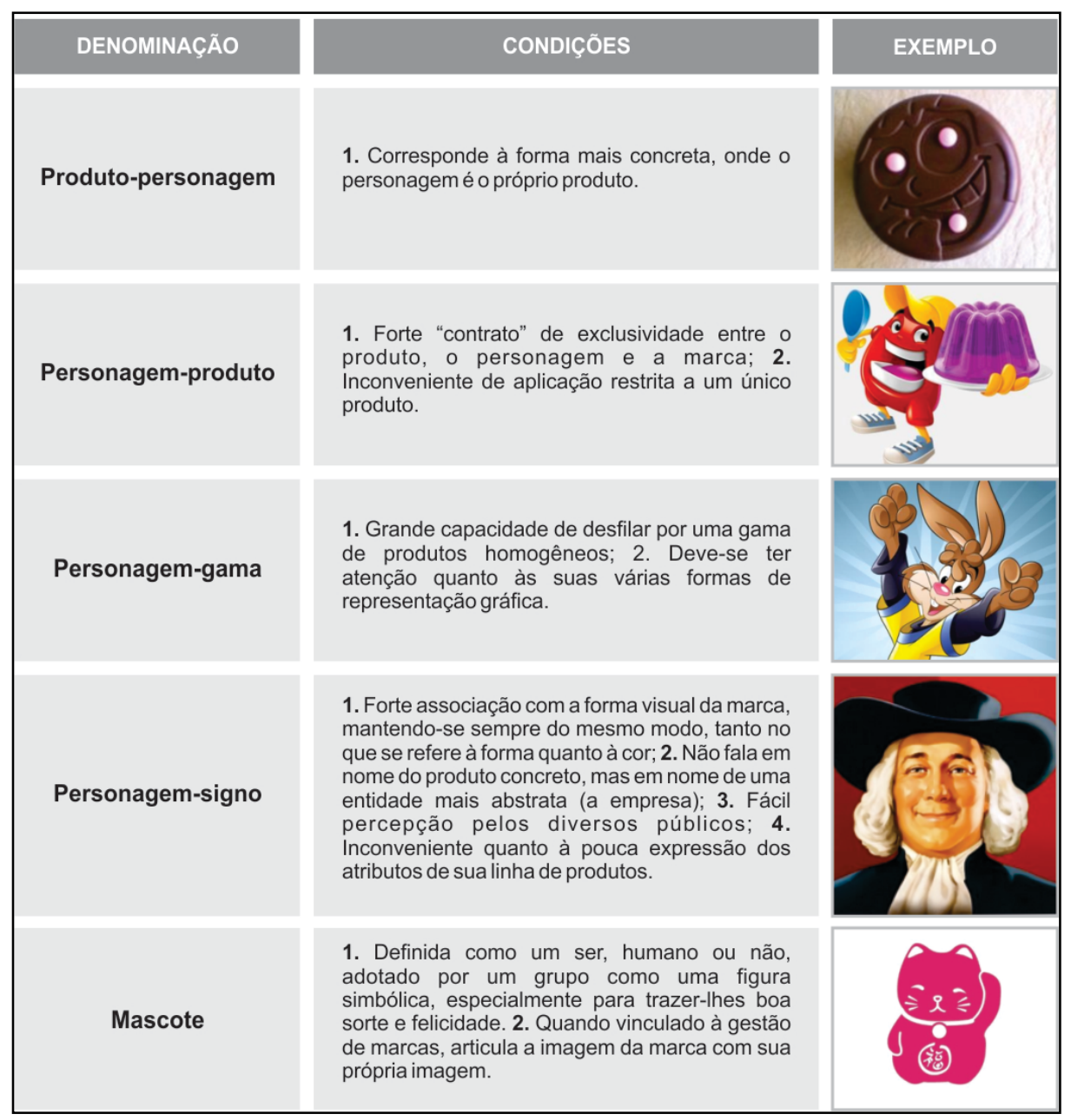

Figura 4:Classificação do Personagem conforme grau de vinculação à marca Fonte: Adaptado de Gomes (2004)

\section{A MASCOTE DA COPA DO BRASIL}

Oficializado pela FIFA e pelo Comitê Organizador Local (COL) da Copa de 2014, após a análise de quarenta e sete propostas de seis agências de publicidade brasileiras, o Tatubola foi escolhido para ser a mascote da Copa de 2014 no Brasil. Criado pela agência 100\% Design, foi identificado como favorito do seu principal público-alvo: crianças de 5 a 12 anos.

É importante destacar que o Tatu-bola é uma espécie vulnerável (ameaça de extinção), afirmou o secretário-geral da FIFA, Jérôme Valcke e acrescentou: 
Com este mascote, vamos poder realizar um dos principais objetivos da Copa do Mundo de 2014, que é comunicar a importância do meio ambiente e da ecologia. Temos certeza de que ele será amado não apenas no Brasil, mas no mundo todo.

O Tatu-bola teve o seu nome escolhido como Fuleco, que soma as palavras "futebol" e "ecologia", pelo público por meio de votação no site oficial da FIFA. A votação contou ainda com mais dois outros nomes: "Amijubi", neologismo que reúne as palavras amizade e júbilo, do Tupi - Guarani; onde juba significa amarelo - a cor predominante do mascote e "Zuzeco", formado pelos elementos do azul (cor do mar brasileiro) e também ecologia.

Ainda que tenha havido inúmeras críticas e reclamações, tanto da imprensa quanto da opinião-pública, quanto às propostas de nomes apresentadas, a FIFA anunciou, por meio de um comunicado oficial, a manutenção do nome escolhido. Segundo declarado, as opções foram se restringindo na medida em que a assessoria jurídica da entidade identificava a (in)disponibilidade de registro junto aos órgão de registro de marcas e patentes internacionais.

A mascote oficial da Copa a realizar-se no Brasil é a mais recente de uma longa linha de personagens que entraram para a história da competição. É uma das principais imagens do Mundial, proporcionando à FIFA, ao Comitê Organizador Local e às demais partes envolvidas, como veículos de comunicação, patrocinadores e empresas interessadas da exploração comercial a partir do licenciamento, uma marca para a realização de campanhas promocionais e de contato com o público.

Segundo Limeira (2008, p. 06), "uma marca é, ao mesmo tempo, um sinal que identifica um produto e um símbolo, é a representação de uma ideia, de um pensamento ou comportamento. Portanto, as marcas têm valor simbólico". Uma marca trabalha com a percepção e, portanto, deve ser forte o suficiente para que possa representar a mensagem correta. E para que seja mais facilmente registrada em nossa mente, é necessário que ela possua uma forma própria e característica.

Para Aaker (1998) quanto mais favoráveis, fortes e exclusivas forem as associações, mais o indivíduo constrói uma percepção de valor de marca, principalmente se a ligação com a marca for baseada em muitas experiências ou exposições a comunicação. E complementa "uma associação de marca é algo ligado a uma imagem na memória" (AAKER, 1998, p.114). Mas, segundo Read (1982), para que isso aconteça, é necessário que este objeto faça parte do mobiliário da nossa mente. Ainda segundo o autor, o cérebro humano recebe, durante toda a sua existência consciente, muitas reflexões que deixam marcas, que são capazes de ser 
revividas e re-experimentadas. Só assim é possível 'reproduzir' ou 'relembrar' o conhecimento e, então, utilizá-lo.

O conhecimento retido do objeto encontra-se, por isso, entre os vestígios de outros conhecimentos retidos, e tem tendência, pela sua mera presença física, para atrair a si aqueles conhecimentos que são relevantes, isto é, que completam o modelo exigido. Se abrirmos a porta para sair e virmos chuva, sabemos imediatamente da existência de objetos que nos protegem da chuva, um guarda-chuva ou uma gabardina. Chamamos associação a este processo de ligação de um ato presente de percepção com um ato revivido de percepção e a faculdade que nos permite reviver o conhecimento das percepções prévias chamamos memória. (READ, 1982).

Para Perassi (2007) uma das maneiras de se conseguir realizar estruturas gráficoexpressivas é justamente através das situações vividas no mundo material. Essas associações produzem denotações figurativas que podem aparecer em três níveis de significação: o nível pré figurativo, o figurativo e o meta figurativo.

Randazzo (1996, p. 27) afirma que a marca "existe num espaço psicológico, na mente do consumidor". Para o autor, a marca funciona como um espelho de valores, refletindo o público e seu estilo de vida. Ela é uma portadora de projeções, facilitada por um inventário perceptual de imagens, símbolos e sensações, que é criado pela própria comunicação (Randazzo, 1996).

Hartmann et al. (1990, p. 122) corrobora a afirmação afirmando que um indivíduo transfere o significado de um objeto aos signos associados a esse objeto que, por sua vez, são transferidos a um novo objeto que possua o mesmo signo.

Para Andraus (2006, p. 05) "a manifestação do desenho como via direta de uma mente que elabora racional e criativamente, expressa os anseios, temores, alegrias e outros humores da pessoa que busca representar graficamente seus estados de ânimo". A caracterização dos personagens, então, deve estar intimamente ligada ao inconsciente coletivo, aos arquétipos pré-estabelecidos pelos padrões sociais de cada cultura.

Nesse sentido, apesar de ser um animal tipicamente brasileiro, o Tatu-bola-daCaatinga, cientificamente identificado como Tolypeutes tricinctus tem seu habitat nas "savanas brasileiras", especialmente na caatinga, bioma que the empresta o nome presente nas regiões centro-oeste e nordeste do país, que ocupa, aproximadamente, apenas $10 \%$ do território nacional. 
Por isso, grande parte da população brasileira jamais viu um Tatu-bola na natureza, ou mesmo em reproduções visuais impressas ou eletrônicas. Tal fato, no entanto, não impede que sua escolha como personagem representativo da 'marca' da Copa do Brasil possa vir a ter sucesso.

Sugere-se, no entanto, que esse fato seja considerado sempre que o animal for apresentado, levando consigo (sua imagem), além da sua denominação real (Tatu-bola) informações que permitam contextualizá-lo e inseri-lo no repertório cultural da população, com as associações necessárias para a sua familiarização, sem a qual a figura ou forma, poderá não vir a ser claramente e corretamente percebida.
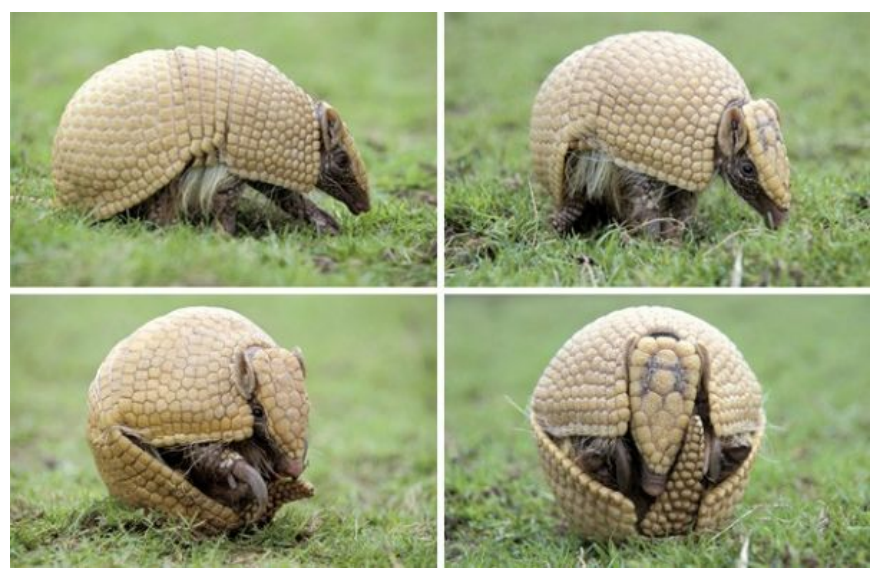

Figura 5: O Tatu-bola (Tolypeutes tricinctus) se defende de predadores enrolando seu corpo. Fonte: http://www.olhardireto.com.br/imgsite/noticias/tatu-bola.jpg

\section{ANÁLISE SEMIÓTICA DA FORMA}

Sendo a mascote um elemento de representação, seja de uma empresa, produto ou evento, adquire, como tal, a função de comunicação dos conceitos vinculados à marca para com seu público. Já em sua origem etimológica, o verbo “comunicar' nos permite compreender a ideia de tornar uma mensagem - no caso da mascote, uma mensagem visual, "comum" aos envolvidos no processo.

Em tal contexto, a representação sígnica torna-se indispensável, pois são os sígnos que fazem a ligação entre as representações de quem emite a mensagem e de quem às recebe. A Semiótica, como a ciência que estudas os signos, torna-se, assim, base da análise do signo da Copa da FIFA 2014, objeto deste estudo. 
O sistema filosófico de Charles Sander Peirce é sustentado na fenomenologia, nas ciências normativas (estética, ética e lógica) e na metafísica. Santaella (2004, p. 9) afirma que a semiótica de Peirce estaria para uma "teoria lógica social do signo". A semiótica peirciana leva em conta a natureza simbólica do ser humano, que possui a capacidade de agregar sentidos aos signos, expressando culturas, e relativizando a própria noção de realidade.

O mundo das imagens se divide em dois domínios. O primeiro é o domínio das imagens como representações visuais: os desenhos e as fotografias pertencem a esse domínio. Imagens, nesse sentido, são objetos materiais, signos que representam o nosso meio ambiental visual. O segundo é o domínio imaterial das imagens na nossa mente. Neste caso aparecem como visões, imaginações, modelos ou representações mentais. (SANTAELLA; NÖTH, 2008, p. 15)

Nesse contexto, Pierce define representar como "estar para", quer dizer, algo está numa relação tal com um outro que, para certos propósitos, ele é tratado por uma mente como se fosse aquele outro" (PIRCE apud SANTAELLA, NÖTH, 2008, p. 17).

Para Santaella e Nöth (2008) na semiótica encontramos definições muito variadas para o conceito de representação que se estende a conceitos semióticos centrais como, por exemplo, o signo.

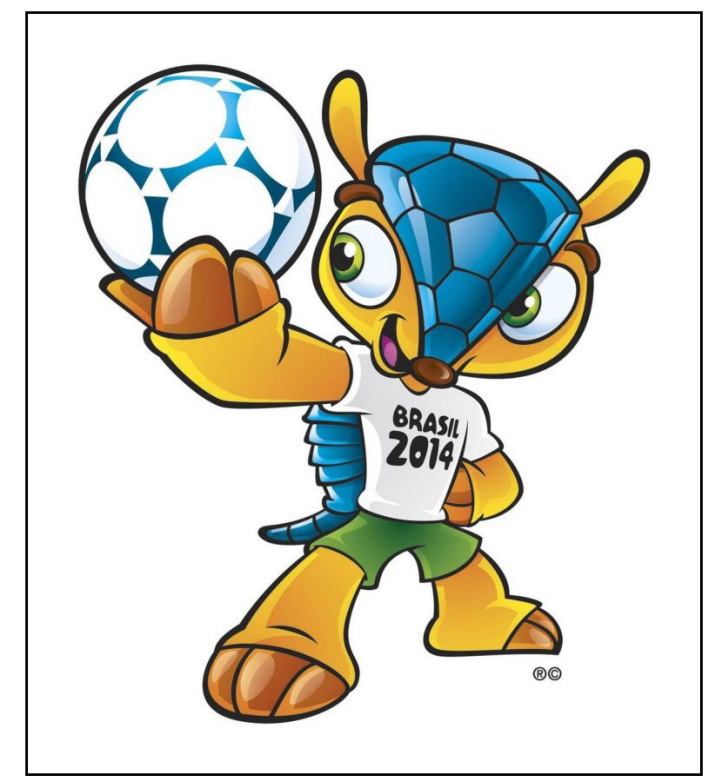

Figura 8: Fuleco, mascote da Copa de 2014 objeto deste estudo. Fonte: http://pt.mascot.fifa.com/index.php 
Para efeito de análise neste artigo, contudo, usaremos o conceito de que signo é qualquer coisa que representa alguma outra coisa a alguém. Neste sentido, a mascote da Copa da FIFA 2014, será analisada como signo e a sua relação com seu objeto dinâmico, bem como com seu interpretante, ou seja, a mascote como índice, como ícone e como símbolo.

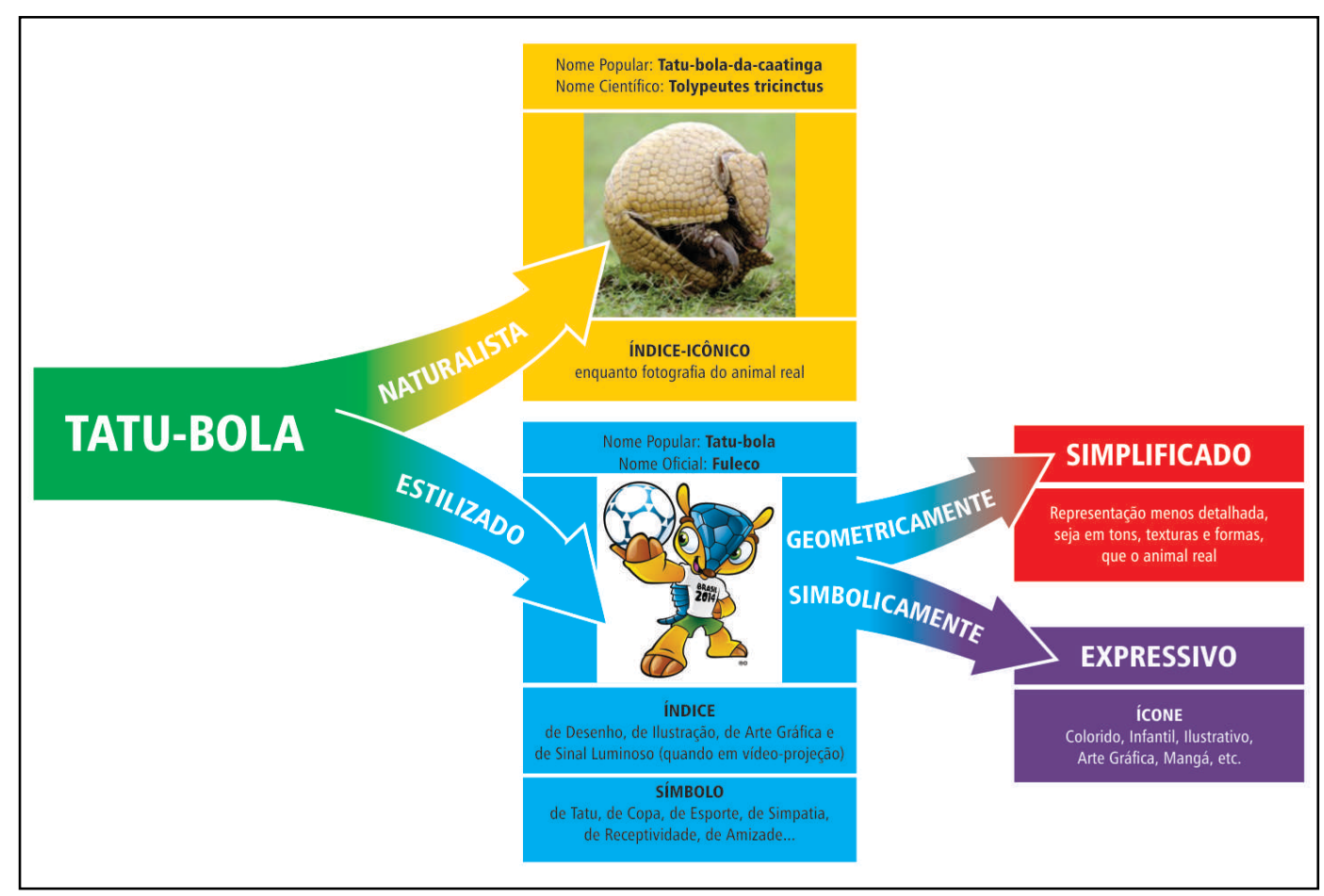

A análise parte da ideia original de "Tatu-bola", que nos permite associar, conforme o repertório cultural de cada indivíduo, com duas representações: a naturalista, ligada à imagem do próprio animal "tatu-bola-da-caatinga", ou Tolypeutes tricinctus, aqui tratado como índiceícônico, uma vez que a imagem é a representação própria e direta do animal real, uma vez que trata-se de uma imagem captada a partir deste. Já a segunda associação passível se dá a partir da representação estilizada do "Tatu-bola". Esta, dada a característica artísticointerpretativa de toda estilização, pode resultar em ínúmeras e diversificadas representações sígnicas. Este estudo, entretanto, atém-se ao 'Fuleco', nome oficial do signo da Copa FIFA 2014, como já foi dito.

Este signo 'estilizado' trata-se tanto de um índice, não de um Tatu-bola, já que pouco há nele além da abstração de um animal real, mas, sim, de uma ilustração, de um desenho 
artístico, de uma arte gráfica, quando esta for o meio de sua apresentação. Ou, ainda, de um índice luminoso, quando apresentado em vídeo ou outro meio de projeção luminosa.

Como índice gráfico, o 'Tatu-Bola Fuleco' possui uma representação geométrica bastante simplificada, se comparada com o índice-icônico da imagem fotográfica do 'Tatubola' da natureza. Dado que, as formas minuciosas, as texturas complexas, as nuances e tons diversificados do animal real são simplificadas no processo de sua 'representação artística'.

Simbolicamente, contudo, este signo gráfico da mascote mostra-se evidentemente mais complexo que o animal que representa. Ao conceder-lhe formas antropomórficas, tonalidades de cores desvinculadas e distantes da sua coloração natural, representação de postura corporal e de movimentos expressivos e repletos de significados, é concedido a este signo uma série de impressões que o tornam, para além do índice gráfico que é, símbolo de Copa, de Brasil, de Simpatia, de Amizade, de Receptividade e, ainda que de forma conceitual, de Tatu.

Neste sentido, passa de índice-gráfico para símbolo de evento esportivo e das representações a ele associadas e, deste, para a conceituação de ícone de representação de temática infantil, de desenho em estilo Mangá, contemporâneo do e identificado com o público para o qual foi criado: crianças de 5 a 12 anos.

\section{CONCLUSÃO}

O estudo realizado acerca da semiótica da mascote da Copa do Mundo de 2014, o 'Tatu-Bola Fuleco', teve como base teórica o sistema de signos desenvolvido pelo filósofo Charles Sanders Peirce. Após fazer uma revisão da literatura, dispondo da história e conceitos sobre mascotes, bem como, sobre a criação da mascote 'Tatu-Bola Fuleco'. O roteiro semiótico utilizado para analisar a mascote, foi apoiado na teoria de Peirce, sugerido por Santaella e Nöth.

A teoria semiótica foi utilizada de forma a analisar todos os aspectos e fenômenos culturais como sistemas sígnicos que possibilitam descrever, analisar e interpretar por meio de linguagem a mascote desenvolvida.

A mascote é uma criatura limiar, que alterna entre o mundo material e a dimensão sobrenatural, entre o tangível e o etéreo, entre o real e o imaginário. Compõe um cruzamento 
entre o humano e o divino. Em outras palavras: as mascotes são artefatos culturais, mas antes de tudo, são um fenômeno cultural.

É notória a importância das mascotes na publicidade, segundo Perez (2011) este é um mundo cheio de cores, de imaginação, de formas, conteúdos e exploração sensorial, por isso tem um forte carisma com o público. São fenômenos sígnicos com muita imaginação e têm uma ligação forte com as expressões daquilo que ele vai se agregar.

Assim, a partir da discussão e análise dos resultados desse estudo semiótico foi possível concluir que para a construção de um personagem é interessante que se insira características de representação, movimentos, impressões que a definam como símbolo para um evento deste patamar, trazendo em sua essência a simpatia, amizade e receptividade.

Nesse contexto, a mascote ganha contornos mais evidentes uma vez que contribui de forma singular com a ampliação da capacidade das marcas construírem vínculos afetivos, características essas que fazem com que o público compreenda a semiótica da mascote.

É possível observar ainda, que o 'Tatu-Bola Fuleco' atinge um público infantil, pois estabelece uma relação entre a marca (copa do mundo no Brasil) e a criança ao nível cognitivo (reconhecimento e memorização da marca) e afetivo (simpatia e atração pela marca).

Vale ressaltar, que o Fuleco é um índice luminoso de uma ilustração, esteticamente traz a sensação de ser colorido, alegre, divertido, é empático, afável e receptivo, também inocente, infantil, macio, volumoso. È um símbolo convencionado que remete a natureza e sustentabilidade e cumpre a função de mascote de futebol, do evento Copa do Mundo 2014 e de seu país-sede, o Brasil.

\section{REFERÊNCIAS BIBLIOGRÁFICAS}

AAKER, David A. Marcas - brand equity: gerenciando o valor de marcas. 10. ed. São Paulo:Elsevier, 1998.

ANDRAUS, Gazy. As histórias em quadrinhos como informação imagética integrada ao ensino universitário. Tese de doutorado. São Paulo: ECA-USP, 2009.

COSTA, Joan. A imagem da marca: Um fenômeno social. Trad.: Osvaldo Antonio Rosiano. São Paulo: Edições Rosari, 2008. (Coleção Fundamentos do Design) 
GOMES, Luiz Cláudio Gonçalves. Mascote: a fiel companhia de uma marca. Anais do P\&D. Brasília: UnB, 2002.

HARTMANN, G. et al. Gestat psychology - A survey of feets and princip. Nova York: Greenwood, 1990.

JUNG, Carl G., et. al. O Homem e seus símbolos. Rio de Janeiro: Nova Fronteira, 1991.

LIMEIRA, Tania Maria Vidigal. Comportamento do consumidor brasileiro. São Paulo: Sara $\mathrm{Va}, 2008$

PACHECO, Lucio. Marcas, imagens, formas e personagens gráficos. Fonte: adonline, 2005. Disponível em: <http://www.adonline.com.br/ad2005/artigos_detalhe.asp?id=44> Acesso em Acesso em 01 de outubro de 2013.

PERASSI, Richard L. S. Gramática Comparada da Representação Gráfica. Revista Convergência, 2007. Disponível em http://convergencias.esart.ipcb.pt/artigo/92. Acesso em out. 2012.

PEREZ, Clotilde. Mascotes: semiótica da vida imaginária. São Paulo : Cengage Learning, 2011.

READ, Herbert. A Educação pela Arte: trad. Ana Maria Rabaça e Luis Filipe Silva Teixeira. São Paulo: Martins Fontes, 1982.

RANDAZZO, S. A criação de mitos na publicidade: como publicitários usam o poder do mito e do simbolismo para criar marcas de sucesso. Rio de Janeiro: Rocco, 1996.

SANTAELLA, Lúcia; NÖTH, Winfried. Comunicação e semiótica. São Paulo: Hacker, 2004.

STRUNCK, Gilberto. Como criar identidades visuais para marcas de sucesso. Rio de Janeiro: Rio Books, 2001.

TELES, L.R.; NUNES, A.S.; GOMES.L.C.G. Dirigindo-se ao público adulto com personagens gráficos infantilizados. $4^{\circ}$ Congresso Internacional de Pesquisa em Design. Rio de Janeiro, 2007.

Tatu-bola é confirmado pela Fifa. Folha-PE: tudo que acontece. 18 set.2012. Disponível em: http://www.folhape.com.br/cms/opencms/folhape/pt/edicaoimpressa/arquivos/2012/09/18_09 2012/0030.html 